\title{
KEARIFAN LINGKUNGAN MASYARAKAT ALOR DALAM NOVEL SWARNA ALOR: IMPIAN DI LANGIT TIMUR KARYA DYAH PRAMESWARIE
}

\section{ALOR COMMUNITY ENVIRONMENTAL WISDOM IN SWARNA ALOR NOVEL: IMPIAN DI LANGIT TIMUR WRITTEN BY DYAH PRAMESWARIE}

\author{
Qhothrun Nadaul Jannah ${ }^{1}$, Purwati Anggraini ${ }^{2}$ \\ Pendidikan Bahasa Indonesia, Universitas Muhammadiyah Malang, Indonesia ${ }^{1,2}$ \\ nadaarbani@gmail.com ${ }^{1}$, poer1979@gmail.com ${ }^{2}$ \\ *penulis korespondensi
}

\begin{tabular}{ll}
\hline Info Artikel & ABSTRAK \\
\hline Sejarah artikel: & Penelitian ini bertujuan untuk mendeskripsikan hubungan manusia dengan \\
Diterima: & alam ditinjau dari nilai-nilai kearifan lingkungan serta upaya \\
3 Desember 2020 & menyeimbangkan lingkungan alam yang dilakukan tokoh dalam novel \\
Direvisi: & Swarna Alor: Impian di Langit Timur karya Dyah Prameswarie. Jenis \\
5 Januari 2021 & penelitian ini adalah kualitatif dengan pendekatan deskriptif. Data dalam \\
Disetujui: & penelitian ini meliputi kutipan terkait hakekat hubungan antara manusia \\
20 Januari 2021 & dengan lingkungannya yang berupa kata, frasa, klausa, dan kalimat. Sumber \\
& data dari novel Swarna Alor: Impian di Langit Timur. Teknik pengumpulan \\
Kata kunci: & data pada penelitian ini menggunakan teknik baca dan teknik catat. Hasil \\
Kearifan, Lingkungan, & penelitian menunjukkan adanya (1) sikap tanggung jawab moral terhadap \\
Alam Masyrakat Alor & alam yang dimiliki oleh masyarakat Alor yang selalu taat terhadap aturan, \\
& tradisi, dan adat dari nenek moyang terdahulu, (2) sikap solidaritas terhadap \\
& alam yang dimiliki oleh tokoh Pak Libana guna mempertahankan tradisi \\
& leluhur dan ekosistem alam, (3) kasih sayang dan kepedulian terhadap alam \\
& yang dimiliki oleh tokoh utama dengan ikut menjadi anggota Green World, \\
dan (4) sikap tidak mengganggu kehidupan alam masyarakat Alor dan selalu & taat pada aturan untuk tidak semena-mena memperlakukan alam.
\end{tabular}

\begin{tabular}{|c|c|}
\hline Article Info & ABSTRACT \\
\hline $\begin{array}{l}\text { Article history: } \\
\text { Received: } \\
3 \text { December } 2020 \\
\text { Revised: } \\
\text { 5 January } 2021 \\
\text { Accepted: } \\
\text { 20 January } 2021 \\
\text { Keywords: } \\
\text { Wisdom, Environment, } \\
\text { Nature of Alor } \\
\text { Community }\end{array}$ & $\begin{array}{l}\text { This study aims to describe the relationship between humans and nature in } \\
\text { terms of environmental wisdom values and efforts to balance the natural } \\
\text { environment by characters in the novel Swarna Alor: Impian di Langit } \\
\text { Timur written by Dyah Prameswarie. This type of research is qualitative } \\
\text { research with a descriptive data approach. The data in this study including } \\
\text { quotes related to the nature of relationship between humans and their } \\
\text { relationship in the form of words, phrases, clauses, and setences. Source of } \\
\text { the data from the novel Swarna Alor: Impian di Langit Timur. Data } \\
\text { collection techniques in this study used the reading technique and note- } \\
\text { taking technique. The result of study show that the (1) is the attitude of moral } \\
\text { resposibility towards nature that is owned by the Alor people who always } \\
\text { obey the traditional and customery rules of their previous ancestors, (2) the } \\
\text { attitude of solidarity towards nature owned by Pak Libana figures in order } \\
\text { to maintain ancestral traditions and natural ecosystems, (3) affection and } \\
\text { concern for nature that are owned by the main by being a member of Green } \\
\text { World, and (4) the attitudes of not disturbing the natural life of Alor people } \\
\text { and always obey the rules not to treat nature arbitrarily. }\end{array}$ \\
\hline
\end{tabular}

Copyright (C 2021, Stilistika: Jurnal Pendidikan Bahasa dan Sastra DOI: http://dx.doi.org/10.30651/st.v14i1.6630 


\section{PENDAHULUAN}

Isu kearifan lingkungan semakin menarik perhatian dunia, karena isu tersebut relevan dengan kondisi sekarang karena permasalahan yang begitu pelik sehingga mengancam dunia menuju kerusakan ekologis yang berkepanjangan. Dapat dipastikan bahwa problem atas isu tersebut hanya akan kembali normal jika manusia berperan aktif dalam hal memelihara keanekaragaman hayati. Hal ini berdasarkan pemikiran dan riset ilmuwan dari berbagai bidang.

Lingkungan dan budaya sejak dahulu telah menjadi bagian citra dari banyaknya ciptaan sastra. Bagaimanapun sebuah karya sastra selalu berhubungan dengan lingkungan dan budaya untuk menghidupkan dan memberi warna suatu cerita. Hal utama yang melatarbelakangi perspektif tersebut adalah kenyataan bahwa Indonesia sangat beragam pesona dan budayanya.

Alor merupakan sebuah pulau yang berada di ujung Timur Kepulauan Nusa Tenggara.Pulau alor merupakan pulau yang memiliki sejuta keindahan baik dari segi alam maupun kekayaan budaya. Salah satu kekayaan budaya etnik dari Pulau Alor adalah kain tenun dan popilaritasnya kian menanjak. Oleh karena itu sampai sekarang masyarakat Alor terus menenun bukan perihal ekonomi mereka, namun juga sebagai usaha pelestarian budaya. Selain keindahan Pulau Alor dan pelestariannya, isu serupa mengenai pemertahanan kearifan lingkungan di Nusa Tenggara Timur yaitu isu penutupan Taman Nasional Komodo untuk Pelestarian. Dikutip dari Tirto.ID, jum'at 23/01 2019) awal pembentukan Taman Nasional komodo guna memelihara dan manjaga komodo dari kepunahan karena di situlah komodo ditemukan. Namun sebaliknya, kian lama ekosistem di Taman Nasional Komodo kian menurun karena keberlangsungan hidup satwa tersebut terancam. Salah satu faktor perubahan ekosistem adalah penurunan populasi rusa sebagai makanan komodo yang teru-terusan diburu.Namun kabarnya hingga kini belum ada tindakan yang ekstrem atau kepastian yang jelas karena menurut Menteri Lingkungan Hidup dan Kehutanan Siti Nurbaya rencana tersebut harus dipertimbangkan dengan perhitungan yang cermat dan perlu didiskusikan lagi.

Kearifan lingkungan dapat dipertahankan dengan cara yang bervariasi agar terhindar dari kerusakan. Fenomena kerusakan lingkungan yang terjadi pada hakikatnya menjerumuskan dua objek, di antaranya manusia dan lingkungan. Masalah lingkungan pada umumnya terkait krisisnya etika manusia saat berhadapan dengan lingkungan alam William Chang, (dalam Setiawan, 2011).

Kerusakan lingkungan tidak hanya terjadi diperkotaan, tetapi juga dipedesaan atau diperkampungan dengan latar belakang soiologis dan masyarakat yang masih memegang teguh adat istiadat. Disatu sisi, masyarakat asli berusaha menjaga keseimbangan alam secara tradisional. Novel Swarna Alor: Impian di Langit Timur oleh Dyah Prameswarie sebagai jawaban atas tuduhan kerusakan lingkungan alam. Novel Swarna Alor: Impian di Langit Timur justru menceritakan bagaimana upaya manusia menyeimbangkan kekuatan alam. dengan tetap menggunakan cara tradisional. Hal ini sesuai dengan 
pendapat Giiford (dalam Nina, 2019) bahwa ekokritik adalah kajian yang tepat terkait prinsip dan nilai moral yang dianut oleh masyarakat tertentu sebagai pedoman dan kriteria dalam berperilaku sebagai manusia dengan kebiasaan hidup yang baik, diturunkan dan diwariskan melalui agama dan kebudayaan yang kemudian dianggap sebagai sumber utama dan nilai moral (Keraf, 2010).

Berdasarkan arketipe ilmu sastra, ekologi merupakan cabang ilmu yang mempelajari tentang makhluk bernyawa dan lingkungannya (Holihah, 2015). . Sederhananya adalah hubungan timbal balik antara antara lingkungan dan makhluk hidupnya.Berdasarkan hal tersebut, dapat dipahami bahwa sastra dan lingkungan merupakan dua hal yang secara konkrit tidak dapat dipisahkan.

Hadirnya berbagai studi interdisipliner, mendorong kemajuan dan perkembangan ilmu ekologi, karena studi ini tidak hanya sebatas telaah tentang alam atau ekosistem tapi juga dimanfaatkan untuk menelaah cabang ilmu lainnya salah satunya adalah sastra. Paradigma hubungannya dengan karya sastra, ekologi digunakan sebagai ilmu dengan definisi yang bevariasi (Endraswara, 2016:33). Pertama, ekologi dipakai untuk mendefinisikan tataran alam. Kedua, ekologi dimanfaatkan secara luas, termasuk mendefinisakan tentang budaya. Ekologi dalam karya sastra seringkali dicitrakan melalui budaya tertentu suatu daerah, maka dari itu budaya yang tampak ikut berdampak terhadap kondisi lingkungan dan sastra, sehingga muncul ekologi budaya (Simaremare, 2017).

Kajian ekologi sastra mempelajari terkait adaptasi manusia dengan lingkungan alam, relasi antara kegiatan manusia, dan proses alam yang saling ketergantungan sebagai suatu komunitas alam. Ecocriticism berasal dari kata ecology dan criticm. Ekologi adalah ilmu yang mempelajari tentang pola hubungan hewan, tumbuhtumbuhan dan manusia terhadap satu sama lain dan terhadap lingkungannya (Ratnawati, 2017). Kritik adalah ekspresi dan bentuk penilaian terkait baik atau buruk dari sesuatu. Demikian dapat dipahami bahwa ekokrtitik adalah penilaian berwawasan terhadap lingkungan, (Harsono dalam Setiawan, 2011).

Swarna Alor:Impian di Langit

Timur karya Dyah Prameswarie merupakan salah satu novel yang bernuansa Indonesia dan mengusung kearifan lingkungan sebagai sumber inspirasi serta isinya memuat banyak perspektif ekologi. Novel ini mengekspos lingkungan budaya serta prevalensi masyarakat Timur khususnya di Kampung Hula Pulau Alor. Pada sisi lain, novel ini menggambarkan bentuk eksploitasi alam yaitu terumbu karang dan biota laut dampak perbuatan manusia yang berkedok Green World.

Masyarakat Hula Pulau Alor merupakan masyarakat yang rata-rata golongan perempuannya menghabiskan waktu untuk menenun. Bahkan sebagai beranggapan bahwa menenun adalah sumber penghasilan mereka. Oleh karena itu, Mama Sariat sebagai salah satu tokoh dalam novel Swarna Alor: Impian di Langit Timur berusaha membuat kain tenun dan mengumpulkan bahan-bahan dari lingkungan yang benar-benar alami agar tidak merusak ekosistem lingkungan.

Penelitian relevan terkait novel Swarna Alor: Impian di Langit Timur pertama, dilakukan oleh Aprilia Mekar 
(Puspitasari, 2016) berjudul 'Aspek Sosial dalam Novel Swarna Alor Kajian Sosiologi Sastra dan Implementasi Sebagai Bahan Ajar Sastra Indonesia di SMP'. Membahas keadaan sosial dalam Novel Swarna Alor: Impian di Langit Timur. Kedua, terkait ekologi lingkungan dilakukan oleh beberapa peneliti. Pertama, penelitian yang dilakukan oleh Fitriah (Nurul Sakina dkk, 2018) yang berjudul 'Relasi Antara Manusia dan Alam' Fitriah dkk mengemukakan bahwa (1) Relasi yang terjalin antara manusia dan alam pada novel Genduk merupakan gambaran hubungan timbal balik antara tokoh dalam cerita dengan alam pegunungan dan (2) Relasi yang terjalin antara manusia dan alam pada novel Genduk memberikan dampak yang mempengaruhi kehidupan beberapa tokoh dan lingkungan sekitarnya.

Perbedaan yang mendasar antara penelitian sebelumnya dengan penelitian ini adalah pada objek yang diteliti. Penelitian sebelumnya menggunakan novel Baiat Cinta di Tanah Baduy karya Uten Sutendy, sedangkan novel ini menggunakan novel Swarna Alor: Impian di Langit Timur karya Dyah Prameswarie. Perbedaan kedua, fokus penelitian sebelumnya mengutamakan masalah perilaku tokoh melakukan gerakan penghijauan. Sedangkan penelitian ini berupaya fokus pada masalah yang lebih umum terkait pemaparan ekologi lingkungan dilihat dari nilai-nilai kearifan lingkungan dan mengungkapkan gagasan yang ditawarkan pengarang berkaitan dengan usaha pemertahanan dan dedikasi tokoh untuk memmelihara lingkungan alam di Pulau Alor.Dengan demikian, diharapkan penelitian ini dapat mengatasi kekurangan atau kelemahan penelitian-penelitian terdahulu.

\section{METODE}

Jenis penelitian ini adalah penelitian kualitatif dengan pendekatan deskriptif yakni kajian analisis teks atau wacana sastra yang mengandung kebenaran bersifat logis dan bersistematika. Jenis penelitian kualitatif merupakan hasil pembahasan penelitian yang bertujuan mendeskripsikan secara jelas yang menjadi rumusan masalah atau pokok penelitian (Ratna, 2010:46). Menggunakan tahap-tahap penafsiran dengan menyajikan dalam bentuk dekskrips. Jenis kualitatif dipakai guna memperoleh data yang mendalam, mengandung makna dibalik data yang tampak. Karakteristik pendekatan deskriptif adalah data yang berupa kata, frasa, klausa dan kalimat yang membentuk pikiran dan ungkapan tokoh dalam novel Swarna Alor:Impian di Langit Timur karya Dyah Prameswarie yang memuat kearifan lingkungan. Hal ini relevan dengan penerapan kualitatif sebagai jenis penelitian yang digunakan.

Sumber data dalam penelitian diperoleh dari dua sumber yaitu sumber data primer dan sumber data sekunder. Sumber data primer merupakan datadata atau kutipan-kutipan yang diperoleh langsung dari novel Swarna Alor:Impian di Langit Timur Karya Dyah Prameswarie yang dimana datadata atau kutipan-kutipan tersebut relevan dan memuat rumusan masalah tadi. Kemudian, yang dimaksud sumber data sekunder adalah data yang diperoleh dari luar, misalnya dari buku atau jurnal artikel sejenisnya yang dijadikan referensi supaya data tetap valid dan bersifat faktual.Adapumn data dalam penelitian ini berupa unit- 
unit teks, baik berupa kata, frasa, klausa, kalimat maupun paragraf yang strukturnya berkaitan dengan rumusan masalah yang dikaji yaitu data-data atau kutipan yang memuat bentuk dan dedikasi pelestarian kearifan lokal.

Teknik pengumpulan data pada penelitian ini menggunakan dua teknik yaitu teknik baca dan teknik catat. Adapun langkah-langkah pengumpulan data yaitu, tahap pertama menyiapkan alat bantu tulis (pensil) untuk menandai bagian atau kutipan yang akan dijadikan data. Kedua, menggunakan teknik baca tadi, yakni membaca keseluruhan isi novel dan berulangulang, dengan tujuan menemukan satuan atau kalimat yang relevan dengan rumusan masalah yang akan dikaji. Ketiga, menandai bagian atau kutipan yang menunjukkan permasalahan yang akan dibahas menggunakan alat tulis (pensil). Keempat, menelaah kembali bagian kutipan yang telah ditandai untuk memastikan kesesuaian data dengan permasalahan sehingga tidak ada data yang tertinggal maupun data yang salah. Kelima, mengelompokkan kutipan-kutipan yang didapat untuk persiapan sub-sub bab pada hasil pembahasan.

Terakhir, data atau kutipan diberi keterangan dan penjelasan dari segi konteks, manfaatnya dan pengaruhnya. Penjelasan yang dipaparkan tidak boleh keluar dari konteks atau permasalahan karena di situ adalah fokus utama pembaca, hal ini untuk menghindari salah kaprah pembaca. Penjelasan juga diuraikan dengan bahasa yang sederhana dan logis agar pembaca yakin dan tulisan pun bersifat konkret.

Instrumen pengumpulan data yaitu, buku atau novel Swarna Alor: Impian di Langit Timur, pensil, ballpoint. Intrumen tersebut digunakan untuk mencatat sekaligus menggambarkan informasi yang di dapat dalam novel.

\section{HASIL DAN PEMBAHASAN}

Swarna Alor: Impian di Langit

Timur mengisahkan kehidupan masyarakat Alor, Nusa Tenggara Timur, yang masih kental dengan adat dan budayanya. Novel tersebut juga menggambarkan kepedulian masyarakat Alor terhadap kondisi lingkungan alam sekitarnya. Mereka merawat, memperlakukan, menyelaraskan alam dengan baik serta hati-hati berdasarkan kearifan yang mereka yakini. Berikut ini adalah pemaparan dan pendeskripsian mengenai nilai-nilai kearifan lingkungan dalam novel Swarana Alor:Impian di Langit Timur.

\section{Sikap Hormat Terhadap Lingkungan Alam}

Sikap hormat terhadap alam, dimaksudkan bahwa manusia perlu menyadari akan kewajiban menjaga dan menghormati hak semua makhluk hidup untuk bertumbuh, berkembang dan hidup (Keraf, 2010:167-168). Prinsip ini berspekulasi bahwa kehidupan manusia sedikit banyak bergantung pada alam dan manusia merupakan anggota dari komunitas ekologis, untuk itu pengkajian ini secara umum memiliki tujuan yang bersifat kualitatif. Kualitatif berarti untuk membuat deskripsi, gambaran atau lukisan secara sistematis, akurat dan aktual mengenai fakta-fakta, sifatsifat serta hubungan antara fenomena yang diselidiki. Pengkajian ini bertujuan untuk menemukan pengetahuan baru serta mengungkapkan hubungan manusia dengan alam ditinjau dari nilai-nilai 
kearifan lingkungan serta upaya menyeimbangkan lingkungan alam yang dilakukan tokoh dalam novel Swarna Alor: Impian di Langit Timur karya Dyah Prameswarie.

Alam memiliki hak untuk kehormatan atau dihormati. Berikut kutipan yang relevan hasil temuan peneliti terkait sikap hormat tokoh terhadap lingkungan. Dalam novelnya, Dyah Prameswarie tidak terlalu menonjolkan sikap hormat tokoh terhadap lingkungan alam. Karena secara integritas pembahasan terkait nilai sikap hormat terhadap lingkungan alam sudah termuat dalam keempat sikap lain.

\section{Sikap Tanggung Jawab Terhadap Lingkungan Alam}

Sikap ini menuntut manusia untuk mengambil aksi nyata dalam menjaga alam semesta secara bersama.Manusia mempunyai tanggung jawab atas pelestarian dari dampak kerusakan alam. Wujud tanggung jawab ini di antaranya; mengingatkan, melarang dan memberi sanksi kepada siapa saja yang merusak dan membahayakan alam secara sengaja. Sikap tanggung jawab terhadap lingkungan ditunjukkan oleh tokoh dalam novel Swarna Alor: Impian di Langit Timur melalui kutipan berikut.

"Justru karena biota laut itu, Ibu” desisku tak sabaran. "Mengambil teripang langsung dari habitatnya akan merusak ekosistem laut, itu tidakboleh. Lama-lama teripang akan jadi binatang langka atau bahkan punah" (SAILT, 2015:46).

\footnotetext{
"Halo,Samara? Kamu harus cepat-cepat ke sini. Mereka
}

$\begin{array}{lr}\text { menggunakan tujuh } & \text { teripang } \\ \text { berbeda jenis } & \text { untuk } \\ \text { mewarnaikain- kain } & \text { itu!" }\end{array}$

(SAILT, 2015:73).

Berdasarkan penggalan kutipan di atas, sikap tanggung jawab terhadap alam dicitrakan oleh tokoh utama melalui ucapan dan tindakan. Tokoh utama sangat peduli terhadap lingkungan, seperti yang sudah dipaparkan pada data hasil temuan sebelumnya. Lilo adalah seorang desainer muda yang berbakat, bahkan karena sikap ini ia berpikir keras karena satu sisi adalah langkah untuk menuju gerbang mimpinya dan kegiatan mengambil teripang langsung secara terus menerus akan memicu kepunahan dan teripang akan menjadi binatang langka. Lilo juga menunjukkan sikapnya dengan perilaku dan menelpon ketua Green World untuk memberantas kegiatan pengambilan teripang.

Sementara itu, melestarikan lingkungan hidup dengan sebaikbaiknya telah membuktikan sikap peduli terhadap lingkungan. Hal ini dapat ditunjukkan melalui aksi mengelola, memelihara, serta menjaga lingkungan hidup. Selayaknya manusia mempunyai kewajiban moral dan tanggung jawab terhadap alam, hal itu bisa ditanamkan dan diimplementasikan dalam kehidupan sehari-hari seperti usaha tokoh Lilo dalam novel Swarna Alor: Impian di Langit Timur yang tidak mau merugikan atau mengancam eksistensi alam dan makhluk hidup secara tidak perlu. Cukup hasil alam kita gunakan seperlunya untuk memenuhi kebutuhan hidup. Sehubungan dengan itu, manusia mempunyai pengaruh penting dalam kelangsungan ekosistem habitat manusia itu sendiri, tindakan-tindakan 
yang diambil atau kebijakan-kebijakan terkait hubungan dengan lingkungan alam akan berpengaruh bagi manusia itu sendiri.

Pulau Alor adalah wilayah pesisir yang strategis karena merupakan wilayah peralihan antara ekosistem darat dan laut, juga memiliki potensi sumberdaya alam yang besar dan lingkungan yang begitu kaya.Tak heran jika dalam memenuhi kebutuhan hidup, masyarakat Alor terbiasa mengandalkan alam. Namun salah satu cara untuk menghindari perilaku eksploitasi seperti pada kutipan diatas adalah dengan mencari alternatif pembangunan yang lain untuk pengelolaan sumber daya alam terutama biodata laut. Selain itu, masyarakat dapat menciptakan peluang dan pemerataan yang ramah lingkungan dan mengandung kearifan tradisional.

\section{Sikap Solidaritas Terhadap Lingkungan Alam \\ Manusia \\ mempunyai}

kedudukan yang sejajar dengan alam dan sesama makhluk hidup lainnya.Hal itu mampu menumbuhkembangnkan rasa solidaritas dalam personalitas manusia (Nurhadi, 2020). Sikap ini gambaran dari sikap untuk turut merasakan apa yang dirasakan oleh alam, sehingga manusia akan berupaya menyelamatkannya. Berikut merupakan data yang dinunjukkan sikap solidaritas tokoh terhadap alam dalam novel Swarna Alor: Impian di Langit Timur.

"Yaaa, kita mati karena telah
mempetahankan tradisi
leluhur."
"Kain-kain itu bagi kami bukan
sekadar benang yang ditenun.
Itu peninggalan tetua,

\begin{abstract}
peninggalan leluhur kami. Dulu beberapa pengrajin menggunakan pewarna kimia. Limbahnya mencemari mata air kami. Lalu mama Sariat mengembalikan semuanya ke alam. Kain-kain itu diwarnai dengan bahan alami dari air sisa rebusan teripang, akar pohon mengkudu, asam dan kunyit, Mama Sariat juga menanam pohon kapas di sekitar rumah" (SAILT, 2015:177).
\end{abstract}

Penggalan kutipan di atas, membuktikan sikap solidaritas salah satu tokoh dalam novel Swarna Alor: Impian di Langit Timur karya Dyah Prameswarie.Tokoh tersebut bersedia dan rela kehilangan nyawa hanya untuk mempertahankan tradisi lingkungan alam. Tokoh tersebut sangat memperhatikan keadaan ekologi tumbuhan dan ekologi hewan laut. Sejak dulu hingga sekarang ketimbang menggunakan pewarna kimia, masyarakat Alor lebih memilih menggunakan pewarna alami dengan cara tradisional. Solidaritas ekologi tanaman, sebagai representasi tokoh menggunakan tumbuhan yaitu semua vegetasi tanaman serta buah sebagai bahan pewarna alami. Pertumbuhan tanaman sangat dipengaruhi oleh lingkungan. Jika manusia memperlakukan lingkungan dengan baik terutama pada tanaman maka efeknya akan baik pula, karena komponen manusia dan lingkungan mempengaruhi fungsi fisiologis tanaman dan akan terlihat pada penampilan tanaman (Rusdina, 2015). Solidaritas ekologi kedua adalah hewan laut, yakni teripang. Teripang merupakan salah satu biota laut yang berpotensi sebagai bahan pewarna alami. Teripang merupakan binatang 
invertebrata yang hidup di laut dan dapat ditangkap ketika laut pasang surut bahkan sampai laut dalam dan aslinya dapat dikonsumsi.

Dengan demikian, keseimbangan antara manusia, alam, dan makhluk hidup lainnya akan menghasilkan sesuatu yang positif apabila keseimbangan tersebut dapat diartikan dan diilhami dengan sikap yang positif pula. Manusia yang memiliki kepekaan yang tinggi terhadap lingkungan alamnya tentu merasakan apa yang sedang terjadi dan dirasakan oleh alam. Perilaku tersebut tanpa sadar dan secara tidak langsung berpengaruh serta sedikit demi sedikit akan menyelarsakan dan mengharmonisasikan perilakunya (Hengky, 2011) . Untuk itu, diharapkan agar segala perilaku dan tindakan sampai merusak lingkungan alam.Sikap solidaritas yang dicitrakan tokoh Pak Libana dapat dijadikan sebagai pengontrol moral manusia.Diantaranya dapat menjaga relasi antara manusia dan alam, mengharmosasikan perilaku manusia dengan segala ekosistemnya, dan membuat manusia mengambil kebijakan pro-alam, pro-lingkungan hidup bahkan menentang segala tindakan yang mengeksploitasi alam.

\section{Sikap Kasih Sayang dan Kepedulian Terhadap Alam}

Nilai sikap kasih sayang dan kepedulian terhadap lingkungan alam dapat dicitrakan melalui ucapan, sikap, tindakan atau perbuatan manusia terhadap lingkungan untuk tidak mengeksploitasi, menyalahgunakan serta memberi perlindungan dan memelihara alam tanpa mengharapkan balasan. Sikap kasih sayang dan kepedulian terhadap alam yang ditemukan pada novel Swarna Alor adalah kutipan, sebagai berikut.

"Seminggu sejak kami berkenalan, aku resmi menjadi anggota Green World. Dengan slogan 'To Make A Better Green World', Green World punya sejumlah misi dan kegiatan khusus remaja. Kami

menjelajah monas, memunguti sampahyang berserakan, dan mengajak pengunjung untuk membantu. Kami juga pergi ke Lembang untuk menanam seribu bibit pohon agar kelak generasi kami bisa menikmati teduhnya hutan" (SAILT, 2015:73).

Nilai sikap kasih sayang dan kepedulian terhadap alam pada kutipan di atas digambarkan melalui tindakan tokoh utama Lilo yang mengikuti gerakan Green World dengan menjadi salah satu anggotanya.Tokoh utama menunjukkan kasih sayang dan kepeduliannya dengan ikut kegiatan menanam pohon dan memunguti sampah.Secara tidak langsung perilaku tokoh menjadi kebiasaan sehingga membentuk karakternya menjadi pribadi yang sayang terhadap lingkungan alam.Sikap kasih sayang dan kepedulian terhadap alam seharusnya timbul pada semua anggota komunitas ekologis, terutama masyarakat sendiri. Semua makhluk hidup mempunyai hak untuk dipelihara, dirawat, dilindungi, dan tidak disakiti. Demikian sikap kasih sayang ini menimbulkan keinginan dan perilaku melindungi dan memelihara alam dengan sebaik-baiknya.

Kasih sayang dan kepekaan manusia terhadap lingkungan alam sangat diperlukan agar alam juga dapat 
menjamin kebutuhan hidup manusia.Alam tidak hanya memberi kehidupan manusia dalam fisik saja, melainkan juga memberikah hidup dalam mental dan spiritual (Rengganis, 2019). Rasa kasih sayang dimiliki oleh manusia yang ditujukan kepada alam secara tersirat akan mewujudkan bentuk-bentuk kepedulian. Demikian juga dalam diri manusia akan tumbuh keinginan dan rasa saling menjaga satu sama lain dan seminimal mungkin tidak saling menyakiti antara satu sama lain. Sesuai dengan hal itu, dalam teori humanisme Abraham Maslow (dalam Nurkamilah, 2018) menyatakan bahwa ada 5 kebutuhan manusia, salah satunya adalah kebutuhan akan kasih sayang. Jadi, tidak menutup kemungkinan bahwa makhluk hidup lain serta lingkungan sekitar juga membutuhkan kasih sayang layaknya manusia.

\section{Sikap Tidak Mengganggu Kehidupan Lingkungan Alam}

Sikap tidak mengganggu kehidupan alam adalah salah satu bentuk nilai tenggang rasa manusia (Efendi, 2018). Nilai toleransi ini berkaitan dan telah terintegrasi dalam empat nilai sebelumnya.Yaitu kemampuan menghormati dan menjaga keberadaan dan keadaan alam disekitar untuk tidak merugikan alam dan membiarkan alam dalam keadaan tidak tersentuh.Sikap tidak mengganggu kehidupan alam ditunjukkan pada kutipan, sebagai berikut.

\section{"Ekosistem terumbu karang sebenarnya mengandalkan}

kerja sama, mulai dari hutan bakau di pesisir pantai dan ekosistem pada lamun, semuanya bekerja dalam satu lingkaran. Itu sebabnya penduduk di daerah pesisir pantai yang terpencil jauh lebih paham dalam menjaga kelestarian alam dibandingkan manusia kota. Itu juga alasan kami menggunakan bahan alami, kami berusaha menyeimbangkan, mengembalikan dan menjaga kelestarian alam" (SAILT, 2015:214).

Kutipan di atas relevan dengan nilai sikap tanggung jawab terhadap alam, dan sikap ini dibuktikan oleh tokoh dalam novel Swarna Alor oleh Dyah Prameswarie dengan menjelaskan secara lisan bentuk tanggung jawab yang mereka emban untuk mempertahankan ekosistem laut dan darat. Dengan demikian, masyarakat berusaha menyeimbangkan keadaan alam dengan mengurangi kegiatan yang menimbulkan kerusakan pada alam mereka. Memelihara dan melestarikan alam merupakan salah satu tugas yang dianggap penting oleh masyarakat Pulau Alor. Masyarakat Alor memanfaatkan alam sebagai salah satu komoditas untuk membantu memenuhi kebutuhan hidup mereka.Tujuannya agar tidak menimbulkan kerusakan ekosistem tanah ketika hendak membuang limbah rebusan teripang tersebut. Data di atas merupakan data langsung yang diperoleh dari novel Swarna Alor: Impian di Langit Timur yang menggambarkan sikap tidak mengganggu alam dengan berusaha mengembalikan kebutuhan hidup ke alam.

\section{PENUTUP}

Pengkajian ini bertujuan untuk menemukan pengetahuan baru serta mengungkapkan hubungan manusia dengan alam ditinjau dari nilai-nilai kearifan lingkungan serta upaya menyeimbangkan lingkungan alam 
yang dilakukan tokoh dalam novel Swarna Alor: Impian di Langit Timur karya Dyah Prameswarie.

Berdasarkan hasil analisis yang penulis temukan tentang kearifan lingkungan terdapat 4 nilai kearifan lingkungan yaitu (1) sikap tanggung jawab moral terhadap alam yang dimiliki oleh masyarakat Alor yang selalu taat terhadap aturan, tradisi, dan adat yang sudah diakui dan diterapkan dari nenek moyang terdahulu, (2) sikap solidaritas terhadap alam yang dimiliki oleh tokoh Pak Libana guna mempertahankan tradisi leluhur dan ekosistem alam, (3) kasih sayang dan kepedulian terhadap alam yang dimiliki oleh utama Lilo dengan ikut menjadi anggota Green World, gerakan peduli lingkungan hidup, dan (4) sikap tidak mengganggu kehidupan alam yang dimiliki oleh masyarakat Alorr yang selalu taat pada aturan untuk tidak semena-mena memperlakukan alam, menyeimbangkan serta mengembalikan alam.

\section{DAFTAR PUSTAKA}

Efendi, F. A. (2018). "Upaya Pelestarian Lingkungan Pesisir dalam Novel Tanjung Kemarau Karya Royyan Julian". Jurna Pendidikan Bahasa dan Sastra, 18, 163-173.

Endraswara, S. (2016). Metodelogi Penelitian Ekologi Sastra: Konsep, Langkah, dan Penerapan. Yogyakarta: Caps.

Hengky K. Baransano, J. C. (2011). "Eksploitasi dan Konservasi Sumberdaya Hayati Laut dan Pesisir di Indonesia". JURNAL BIOLOGI PAPUA, 3, 39-45.

Holihah, M. (2015). "Kearifan Ekologis Budaya Lokal
Masyarakat Adat Cigugur Sebagai Sumber Belajar IPS". JPIS, Jurnal Pendidikan Ilmu Sosial, 24, 163-164.

Keraf, A. S. (2010). Etika Lingkungan Hidup . Penerbit Buku Kompas.

Nina Queena Hadi Putri, N. F. (2019). "Kearifan Lingkungan Masyarakat Dayak Benuaq dalam Novel Api Awan Asap: Kajian Ekokritik Giiford". Satwika, 3, 132-141.

Nurhadi, R. A. (2020). "Kearifan Lingkungan dalam Novel Berkelana dalam Rimba Karya Mochtar Lubis". Jurnal Bahasa, Sastra dan Pengajarannya, 4, 152-164.

Nurkamilah, C. (2018). "Etika Lingkungan dan Implementasinya dalam Pemeliharaan Lingkungan Alam pada Masyrakat Kampung Naga". Jurnal Studi Agama-agama dan Lintas Budaya, 2, 136-148.

Prameswarie, D. (2015). Swarna Alor: Impian di Langit Timur. Solo: Tiga Serangkai.

Ratna, N. K. (2016). Metodelogi Penelitian Kajian Budaya dan Ilmu Sosial Humaniora Pada Umumnya. Yogyakarta: Pustaka Pelajar.

Ratnawati, N. F. (2017). "Kearifan Lokal yang Terkandung dalam Novel Amelia Karya Tere Liye". Jurnal bahasa Indonesia dan Pembelajaran, 4, 20-28.

Rengganis, R. R. (2019). "Rerpresentasi Keindahan dan 
Kesadaran Lingkungan dalam Novel Indonesia Kontemporer: Kritik Sastra Berperspektif Ekologi”. Jurnal Lentera, 2, 97115.

Rusdina, A. (2015). "Membumikan Etika Lingkungan Bagi Upaya Membudayakan Pengelolaan Lingkungan Yang Bertanggung
Jawab". Jurnal Istek 9.2 , IX, 244-263.

Setiawan, I. K. (2011). "Usaha-usaha Pelestarian Lingkungan Hidup pada Masyarakat Bali Kuno berdasarkan Rekaman Prasasti”. Bumi Lestari Journal of Environment, 11, 355-359. 